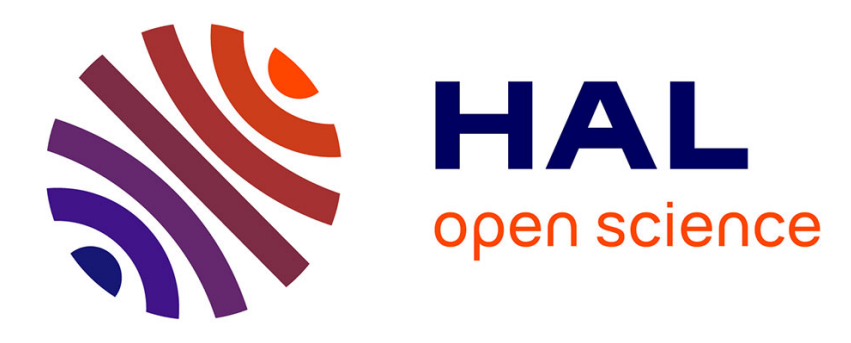

\title{
Platinum-Catalyzed Assembly of Quinaldine from Aniline and Ethylene
}

\author{
Aurélien Béthegnies, Pavel Dub, Rinaldo Poli
}

\section{To cite this version:}

Aurélien Béthegnies, Pavel Dub, Rinaldo Poli. Platinum-Catalyzed Assembly of Quinaldine from Aniline and Ethylene. Organometallics, 2013, 32 (6), pp.1882-1891. 10.1021/om400020k . hal02907523

\section{HAL Id: hal-02907523 \\ https://hal.science/hal-02907523}

Submitted on 3 Mar 2021

HAL is a multi-disciplinary open access archive for the deposit and dissemination of scientific research documents, whether they are published or not. The documents may come from teaching and research institutions in France or abroad, or from public or private research centers.
L'archive ouverte pluridisciplinaire HAL, est destinée au dépôt et à la diffusion de documents scientifiques de niveau recherche, publiés ou non, émanant des établissements d'enseignement et de recherche français ou étrangers, des laboratoires publics ou privés. 


\title{
Platinum-catalyzed assembly of quinaldine from aniline and ethylene
}

\author{
Aurélien Béthegnies, ${ }^{a, b}$ Pavel A. Dub ${ }^{a, b}$ and Rinaldo Poli ${ }^{* a, b, c}$ \\ ${ }^{a}$ CNRS, LCC (Laboratoire de Chimie de Coordination), 205 route de Narbonne, \\ BP 44099, F-31077 Toulouse Cedex 4, France. \\ ${ }^{\mathrm{b}}$ Université de Toulouse, UPS, INPT, F-31077 Toulouse Cedex 4, France \\ c Institut Universitaire de France, 103, bd Saint-Michel, 75005 Paris, France
}

KEYWORDS: Platinum, hydroamination, quinoline synthesis, ethylene complexes, aniline, quinaldine. 
TABLE OF CONTENTS GRAPHIC.

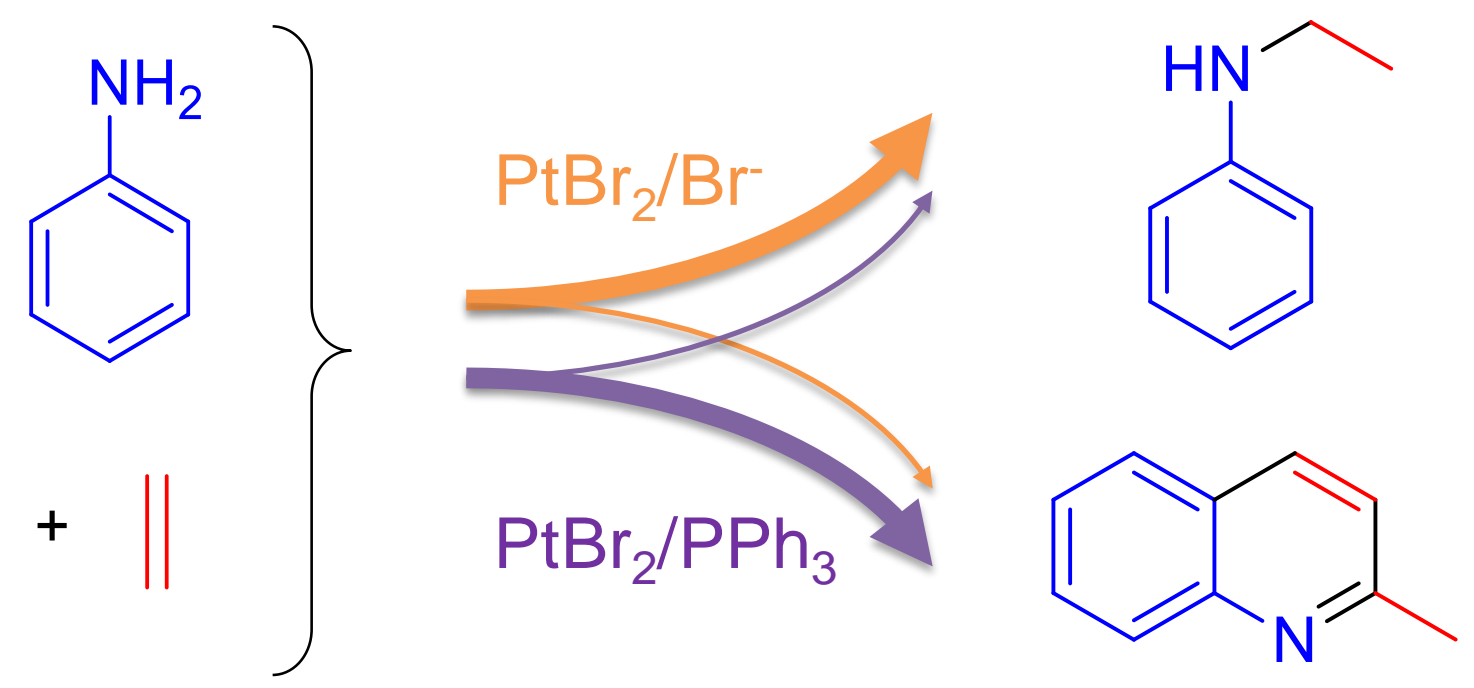


ABSTRACT (Word Style "BD_Abstract").

The selectivity of the catalytic reaction between aniline and ethylene in the presence of the Brunet catalyst $\left(\mathrm{PtBr}_{2} / \mathrm{Br}^{-}\right)$shifts from the hydroamination product $N$-ethylaniline to the heterocyclization product 2-methylquinoline (quinaldine) when conducted in the presence of $\mathrm{PPh}_{3}$ (1 equivalent per Pt atom). Condition optimization revealed that this process works best in the absence of any halide salt additive, that it is essentially insensitive to the nature of the halide in $\mathrm{PtX}_{2}$, that the best promoter in the $\mathrm{PMe}_{\mathrm{x}} \mathrm{Ph}_{3-\mathrm{x}}$ series is $\mathrm{PPh}_{3}$ when used in strictly stoichiometric amounts, and that the $4-\mathrm{RC}_{6} \mathrm{H}_{5} \mathrm{NH}_{2}\left(\mathrm{R}=n \mathrm{Bu}, \mathrm{Cl}, \mathrm{OMe}, \mathrm{NMe}_{2}\right)$ substrates are equally converted albeit less efficiently. Slight dilution of the system with THF or toluene slightly improves the activity and a kinetic profile shows the presence of an induction phase and a deactivating step, which however does not involve reduction to metallic platinum contrary to the $\mathrm{PPh}_{3}$-free Brunet catalyst. Mechanistic considerations are presented. 


\section{Introduction}

The synthesis of quinoline derivatives ${ }^{1}$ is the subject of intense research because of the presence of the quinoline scaffold in a number of biologically active compounds such as antimalaria, ${ }^{2}$ anti-inflammatory, ${ }^{3}$ anti-asthmatic, ${ }^{4}$ anti-bacterial, ${ }^{5}$ anti-hypertensive ${ }^{6}$ and tyrosine kinase inhibiting agents. ${ }^{7}$ In addition, quinoline molecules, metal complexes and polymers are being investigated as materials for electronic and optoelectronic applications. ${ }^{8-10}$ The simplest quinoline derivative is 2 -methylquinoline, or quinaldine. It finds applications as anesthetic, ${ }^{11}$ in bioimaging, ${ }^{12}$ as sensitizers for photodynamic therapy, ${ }^{13-15}$ and in the preparation of a number of other heterocyclic compounds.

Several methods are available to access quinolines, ${ }^{16-18}$ including the syntheses of SkraupDoebner-Von Miller, ${ }^{19,20}$ Pfitzinger ${ }^{21}$ and Conrad-Limpach, ${ }^{22}$ which however suffer from drastic operating conditions and low stereoselectivity, conjugated to multi-step syntheses from commercially available starting materials that negatively affect the overall yields. The Friedländer method is generally considered as the most versatile, even though its use is limited by the need to use unstable aminobenzaldehydes. ${ }^{23}$ Several approaches to access the quinoline skeleton using organometallic catalysis have been developed, such as the condensation of aniline and allyl alcohols, ${ }^{24,25}$ triallylamines,${ }^{26}$ allylammonium chlorides ${ }^{26}$ or alkyl amines, ${ }^{27}$ or the $\mathrm{Ru}-$ catalyzed ring closing metathesis of $\alpha$ - $\omega$-dienes derived from 2 -isopropenylaniline. ${ }^{28-30}$ Other approaches are the palladium catalyzed intramolecular hydroamination of $o$-allylaniline, ${ }^{31}$ the Sonogashira coupling of 2-iodoaniline with acetylenic carbinols, ${ }^{32,33}$ the nickel catalyzed cyclization of 2-iodoanilines with aroylalkynes, ${ }^{34}$ and other catalyzed transformations inspired by the Friedländer synthesis. ${ }^{35,36}$ 
Quinaldine was shown to also form as by-product of the hydroamination of ethylene with aniline (Scheme 1), a transformation that looks attractive since it constitutes a single step from simple and inexpensive starting materials. The reaction was apparently first reported by Diamond et al. with use of $\mathrm{RhCl}_{3} / 2 \mathrm{PPh}_{3}^{37,38}$ and $\mathrm{PdCl}_{2} / 2 \mathrm{PPh}_{3}{ }^{38}$ as catalysts. More recent contributions from Brunet et al. have shown that the catalytic activity of the rhodium system in hydroamination is greatly enhanced by the addition of a soluble iodide salt, also leading to substantial amounts of the double hydroamination product $\left(\mathrm{PhNEt}_{2}, 2\right)$ and small amounts of quinaldine (3, Scheme 1) ${ }^{39}$ and have disclosed for the first time the activity of the platinum system $\mathrm{PtX}_{2} / n \mathrm{Bu}_{4} \mathrm{PY}(\mathrm{X}, \mathrm{Y}=\mathrm{Cl}, \mathrm{Br}, \mathrm{I})$ for this reaction. ${ }^{40}$ The nature of $\mathrm{X}$ in the platinum salt is irrelevant, whereas that of $\mathrm{Y}$ is important: the best promoting system is $n \mathrm{Bu} 4 \mathrm{PBr}$ when used in moderate amounts (10 equivalents relative to $\mathrm{Pt}) .{ }^{41}$ An aqueous biphasic version of this catalytic process using $\mathrm{NaBr}$ as promoter has also been reported. ${ }^{42}$ This catalyst system, however, is haunted by reduction of $\mathrm{PtBr}_{2}$ to inactive metallic $\mathrm{Pt}$, a phenomenon that we have been actively investigating in our laboratory. ${ }^{43-46}$ Brønsted basicity appears to be the cause of this catalyst deactivation process. It should be mentioned that Brønsted acids are known to promote the catalytic activity of metal complexes and to catalyze the hydroamination reaction by themselves in certain cases. ${ }^{47}$ Whereas the addition of Brønsted acids was shown by Brunet to improve the performance of his catalyst, ${ }^{40}$ we have demonstrated that the role of Brønsted acidity in this system is only to prolong the catalyst lifetime by retarding its reductive deactivation by bases. 


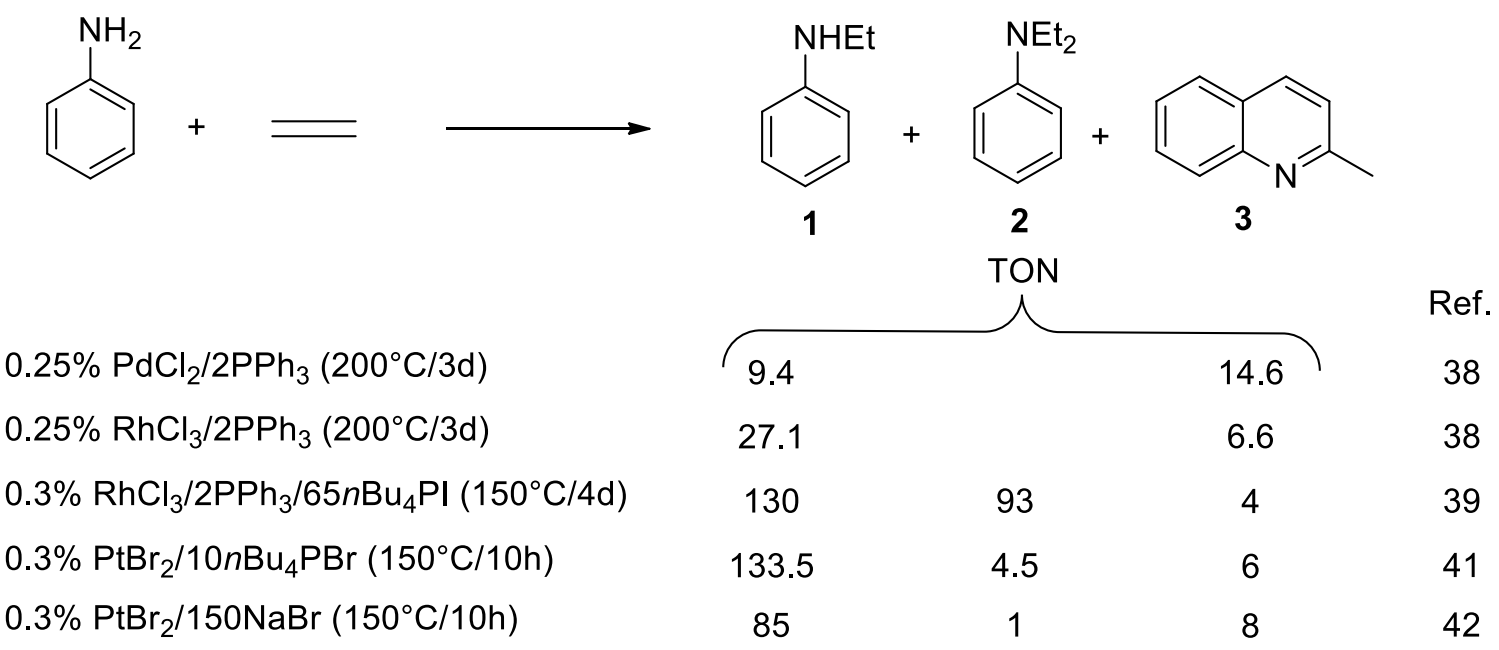

Scheme 1. Products of the metal-catalyzed hydroamination of ethylene by aniline.

No quinoline derivative formation was initially reported from the reaction involving 1-hexene in place of ethylene, ${ }^{48}$ but a later study revealed that $N$-hexylaniline, the anti-Markovnikov product of hexene hydroamination, generates 2-pentyl-3-butylquinoline and aniline under the hydroamination catalytic conditions either in the presence or in the absence (Scheme 2, a) of additional hexene. ${ }^{49}$ In the same study it was also shown that a quinoline derivative resulted from an alkyl transfer process when aniline was exposed to tri- $n$-butylamine (Scheme 2 , b). Furthermore, our own investigations of the hydroamination catalyst decomposition have revealed that alkyl transfer processes also occur for aliphatic amines (e.g. $\mathrm{Et}_{2} \mathrm{NH}$ generates $\mathrm{Et}_{3} \mathrm{~N}$ and $\mathrm{EtNH}_{2}$ ), that this process may occur via retro-hydroamination (e.g. Et $3 \mathrm{~N}$ generates an observable amount of $\mathrm{Et}_{2} \mathrm{NH}$ ), and that this reaction is catalyzed by metallic $\mathrm{Pt}$ and not by the $\mathrm{PtBr}_{2} / \mathrm{Br}^{-}$ hydroamination catalyst. ${ }^{44}$ Hence, the amine Brønsted basicity induces reduction of $\mathrm{PtBr}_{2}$ to $\mathrm{Pt}^{0}$ which in turn catalyzes alkyl transfer and retro-hydroamination processes to generate olefins in situ and subsequently the quinoline formation may occur with catalysis by either $\mathrm{Pt}^{\mathrm{II}}$ or $\mathrm{Pt}^{0}$. $\mathrm{A}$ 
relevant result is also the rhodium-catalyzed quinoline synthesis by addition of aromatic amines to styrenes, for which a certain scope was reported (Scheme 2, c) ${ }^{50}$

(a)<smiles>CCCCCCNc1ccccc1</smiles>

(b)

(c)<smiles>[R]c1ccc(C=C)cc1</smiles>

TON:

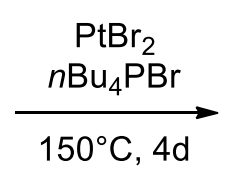

TON:<smiles>Nc1ccccc1</smiles>

3

Ref.

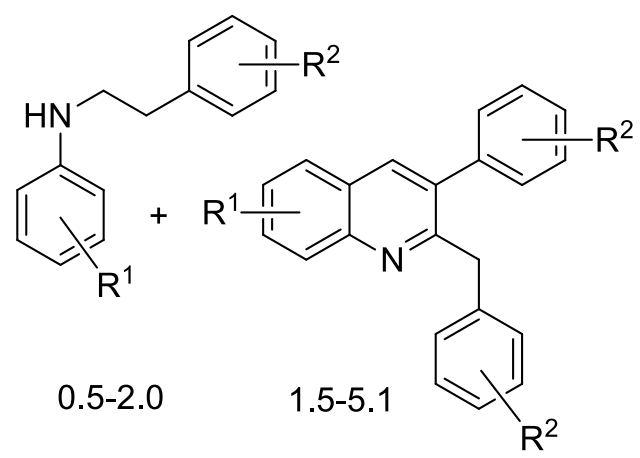

$\mathrm{R}^{1}=\mathrm{H}, 3-\mathrm{F}, 4-\mathrm{F}, 3-\mathrm{MeO}, 4-\mathrm{MeO}, 4-\mathrm{Me}$, 4-Ph

$\mathrm{R}^{2}=\mathrm{H}, 4-\mathrm{F}, 4-\mathrm{MeO}, 3,4-\mathrm{OMe}, 4-\mathrm{Me}, 3-\mathrm{CF}_{3}$

Scheme 2. Other reports of quinoline formation from anilines.

The mechanism leading to the construction of a quinoline core from an aniline derivative and two molecules of olefin has been addressed by several authors. ${ }^{27,38,49,50}$ The scheme that has emerged so far (see Scheme 3 for the special case of aniline and ethylene) involves a sequence of various steps, not necessarily all metal catalyzed, starting with oxidative amination to yield an enamine 5, tautomerization to the imine 6, aza-Diels-Alder condensation between the enamine 
and the imine leading to the intermediate 8 (this was proposed to occur stepwise via intermediate 7), aniline elimination to yield the dihydroquinoline 9 which is finally aromatized to the quinaldine 3, but can also capture part of the $\mathrm{H}_{2}$ produced in other steps to yield tetrahydroquinoline (4, also observed in certain cases). The current state of knowledge, however, is insufficient to claim full understanding of this mechanism and its relationship with that of the hydroamination process.

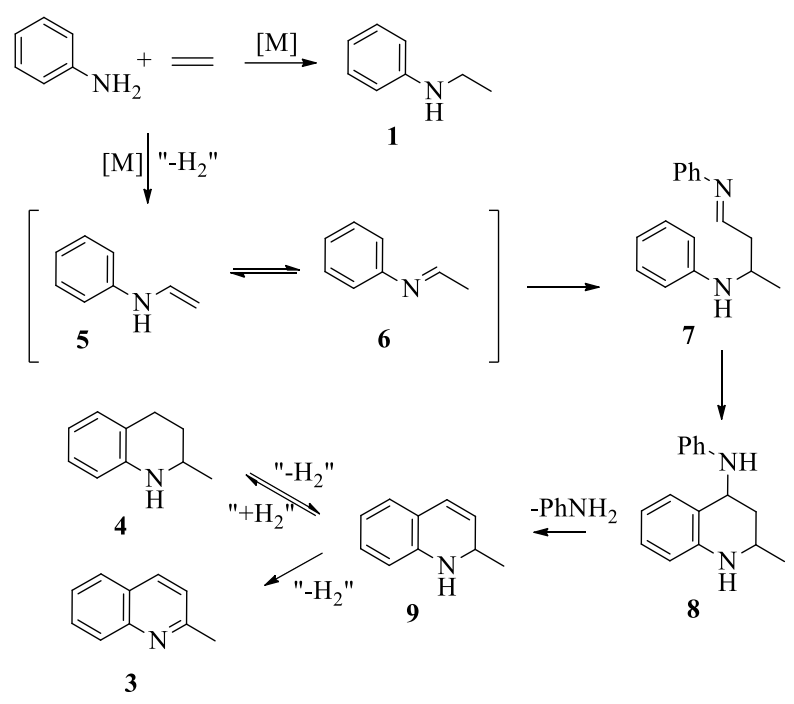

Scheme 3. Proposed general mechanism for the metal-catalyzed quinoline skeleton formation from aniline and ethylene.

Contrary to the rhodium catalyst, the $\mathrm{PtBr}_{2} / \mathrm{Br}^{-}$catalytic system is poisoned by the addition of neutral ligands that are capable to bind platinum. The addition of DMF, DMSO, and notably phosphines ( 2 equivalents) dramatically reduces the catalytic activity for both the hydroamination and heterocyclization processes, whereas the addition of water or ethanol has no noticeable effect. ${ }^{40,42}$ On the other hand, Wang and Widenhoefer have shown that the $\left[\mathrm{PtCl}_{2}\left(\mathrm{C}_{2} \mathrm{H}_{4}\right)\right]_{2} / \mathrm{PPh}_{3}$ catalytic system is active for the intermolecular hydroamination of ethylene 
with carboxamides, provided that a P:Pt ratio of 1 is used. This catalytic system gives better results than the phosphine-free $\left[\mathrm{PtCl}_{2}\left(\mathrm{C}_{2} \mathrm{H}_{4}\right)\right]_{2}$, e.g. a $>98 \%$ conversion for the addition of benzamide $\left(2.5 \%\right.$ catalyst, $24 \mathrm{~h}$ at $120^{\circ} \mathrm{C}$ in dioxane) $v s .44 \%$ conversion in the absence of $\mathrm{PPh}_{3}$. However, use of a P:Pt ratio of 2 resulted in no conversion. ${ }^{51}$ On the basis of this report, we decided to study the effect of phosphines on the catalytic activity of the Brunet system $\left(\mathrm{PtBr}_{2} / \mathrm{Br}^{-}\right)$in ethylene hydroamination by aniline in greater detail. We report here that the system remains indeed active when $\mathrm{P}: \mathrm{Pt}=1$ but the reaction selectivity shifts in favor of quinaldine. Optimization of the catalytic conditions and an analysis of the effect of various additives are also reported.

\section{Experimental Section}

General. Unless otherwise stated, all operations were carried out under an argon atmosphere by using standard Schlenk line techniques. The solvents used were dehydrated using standard procedures and distilled under argon prior to use. Compounds $\mathrm{PtBr}_{2}$ (99.9\%, Aldrich), $\mathrm{PtCl}_{2}$ (99.9\%, Aldrich), $\mathrm{PtI}_{2}$ (Alfa Product), $\mathrm{K}_{2} \mathrm{PtCl}_{4}$ (Strem), $\mathrm{CF}_{3} \mathrm{SO}_{3} \mathrm{H}$ (Fluka, $>98 \%$ ), $\mathrm{NaBr}$ (Aldrich $99 \%$ ), $n \mathrm{Bu} 4 \mathrm{PBr}$ (98\%, Aldrich), $\mathrm{PPh}_{3}$ (Alfa Aesar 99+\%), triphenylphosphine-3,3',3"-trisulfonic acid trisodium salt (TPPTS, Sigma-Aldrich, $>95 \%$ ) and $\mathrm{KBr}$ (Alfa Aesar $99 \%$ ) were used as received. Compound $n \mathrm{Bu} 4 \mathrm{PI}$ was prepared from $n \mathrm{Bu}_{3} \mathrm{P}$ and $n \mathrm{BuI}$ as described in the litterature ${ }^{52}$ and stored in a freezer protected from light. $\mathrm{PMe}_{3}(1 \mathrm{M}$ toluene solution, Aldrich) was used as received and stored in a freezer protected from light. $\mathrm{PMe}_{2} \mathrm{Ph}$ (Strem 99 \%), $\mathrm{PMePh}_{2}(\mathrm{Strem} 99$ \%), $\mathrm{PhNH}_{2}$ (Acros Organics, 99\% for analysis ACS), NEt (Acros Organics 99+\%), 4-(nbutyl)aniline (TCI $>98 \%$ ) and N,N-diethyl-p-phenylenediamine (Aldrich $97 \%$ ) were distilled 
and kept under argon protected from light. 4-nitroaniline (Fluka), $p$-anisidine (Acros $99 \%$ ) and 4-chloraniline (Aldrich) were sublimed prior to use. Compound Diethyl(6-(2methylquinolin))amine was prepared according to a literature procedure. ${ }^{53}$ Ethylene (N25, $\geq 99.5 \%$ ) was obtained from Air Liquide.

Instrumentation. The gas chromatographic analyses were carried out in a Hewlett-Packard HP4890 instrument equipped with HP 3395 integrator, an HP1 capillary column (30 m x 0,320 $\mathrm{mm} \times 0,25 \mu \mathrm{m}$; DB-5MS) and a flame ionization detector, operating with helium as carrier gas at a $50 \mathrm{kPa}$ pressure $\left(\mathrm{T}_{\text {ini }}\right.$ of $65^{\circ} \mathrm{C}$ for $2 \mathrm{~min}$, then $6{ }^{\circ} \mathrm{C} / \mathrm{min}$ up to $\mathrm{T}_{\text {final }}$ of $200{ }^{\circ} \mathrm{C}$ for $\left.30 \mathrm{~min}\right)$. Under these conditions, the retention times of the main compounds are: aniline, $6.8 \mathrm{~min}$; N-ethylaniline, $11 \mathrm{~min}$; N,N-diéthylaniline, $12 \mathrm{~min}$; quinaldine, $15 \mathrm{~min}$; N,N-di- $n$-butylaniline external standard, $21 \mathrm{~min}$. The GC/EI-TOF-MS analysis was performed by the Mass Spectrometry Service of the Universite Paul Sabatier. The ${ }^{1} \mathrm{H}$ NMR investigations were carried out at $298 \mathrm{~K}$ on Bruker DPX300 and AV300 spectrometers.

Catalytic tests with $\mathrm{PtBr}_{2} / \mathbf{P P h}_{3} / \mathbf{n B u} 4 \mathbf{P X}(\mathrm{X}=\mathbf{C l}, \mathbf{B r}, \mathbf{I})$. The reactions were conducted in a $100 \mathrm{~mL}$ stainless steel autoclave in the presence of a magnetic stirrer. The platinum salt $\mathrm{PtBr}_{2}$ (46.1 mg, $0.13 \mathrm{mmol}$ ), triphenylphosphine $(34.1 \mathrm{mg}, 0.13 \mathrm{mmol})$, and the appropriate type and amount (see Results and Discussion) of $n \mathrm{Bu}_{4} \mathrm{PX}$ salt were introduced inside the autoclave, which was then closed and submitted to several vacuum/argon cycles. Aniline (4.1 mL, $45 \mathrm{mmol}, 350$ equivalents) was then introduced by syringe through a septum valve and the autoclave was then charged with ethylene (25 bars, ca. $100 \mathrm{mmol}$ ) and brought to the reaction temperature, $150{ }^{\circ} \mathrm{C}$. After $10 \mathrm{~h}$, the autoclave was cooled to room temperature and then vented. The reaction mixture was transferred into diethylether $(120 \mathrm{~mL})$ and the resulting suspension was stirred for $2 \mathrm{~h}$. The 
external standard $\mathrm{N}, \mathrm{N}$-di- $n$-butylaniline $(\approx 0,15 \mathrm{~g})$ was then added, followed by filtration and GC analysis.

Catalytic tests with $\mathbf{P t X} \mathbf{X}_{2} / \mathbf{P P h}_{3}(\mathbf{X}=\mathbf{C l}, \mathbf{B r}, \mathbf{I})$. The reaction was conducted as described in the previous section, using $\mathrm{PtX}_{2}(0.13 \mathrm{mmol})$ and triphenylphosphine $(34.1 \mathrm{mg}, 0.13 \mathrm{mmol})$ as the only solid reagents. Aniline and ethylene were used in the same amounts and the reaction was carried out for the same length of time at the same temperature. The work-up procedure and the analysis were also identical to those described in the previous section.

Catalytic runs in diluted media. The reactions were conducted as described in the previous section, using $\mathrm{PtBr}_{2}(46.1 \mathrm{mg}, 0.13 \mathrm{mmol})$ and triphenylphosphine $(34.1 \mathrm{mg}, 0.13 \mathrm{mmol})$. In addition to aniline ( $4.1 \mathrm{~mL}, 45 \mathrm{mmol}, 350$ equivalents), a solvent of the appropriate type and amount (see Results and Discussion) was also introduced by syringe through a septum valve. The reactions were carried out at $150^{\circ} \mathrm{C}$ for either 10 or $19 \mathrm{~h}$. The work-up procedure and the analysis were carried out as described in the previous sections.

Kinetic profile. These reactions were conducted as described in the previous sections, using $\mathrm{PtBr}_{2}(92.2 \mathrm{mg}, 0.26 \mathrm{mmol})$, triphenylphosphine $(0.34 \mathrm{mg}, 0.13$ equiv), aniline $(8.3 \mathrm{~mL}, 90$ mmol, 350 equivalents), toluene $(5 \mathrm{~mL})$ and ethylene $(25$ bars $)$, at $150^{\circ}$ C. Samples of ca. $0.5 \mathrm{~mL}$ were withdrawn from the reactor through a siphon at appropriate intervals and added to $3.5 \mathrm{~mL}$ of diethylether and stirred. After adding the external standard N,N-di-n-butylaniline (ca. 0.010 g), the mixture was filtered and analyzed by GC.

Catalytic tests with variable amounts of $\mathbf{P P h}$. These reactions were conducted as described in the previous sections, using $\mathrm{PtBr}_{2}(46.1 \mathrm{mg}, 0.13 \mathrm{mmol})$, the appropriate amount of triphenylphosphine (see Results and Discussion), aniline (4.1 mL, $45 \mathrm{mmol}, 350$ equivalents), 
toluene $(5 \mathrm{~mL})$ and ethylene $(25$ bars $)$ for 10 hours at $150^{\circ} \mathrm{C}$. The work-up procedure and the analysis were also identical to those described in the previous section.

Catalytic tests with different phosphines (PMe3, $\mathrm{PMe} 2 \mathrm{Ph}, \mathrm{PMePh}, \mathrm{PPh}$ ). These reactions were conducted as described in the previous sections, using $\mathrm{PtBr}_{2}(46.1 \mathrm{mg}, 0.13 \mathrm{mmol}$ ), the appropriate type of phosphine ligand ( 0.13 equiv), aniline ( $4.1 \mathrm{~mL}, 45 \mathrm{mmol}, 350$ equivalents), toluene $(5 \mathrm{~mL})$ and ethylene $(25$ bars $)$, for 10 hours at $150^{\circ} \mathrm{C}$. The work-up procedure and the analysis were also identical to those described in the previous section.

Catalytic tests with 4-(R)aniline, $\mathrm{R}=\mathrm{NO}_{2}, n \mathrm{Bu}, \mathrm{MeO}, \mathrm{NEt}_{2}, \mathrm{Cl}$. These reactions were conducted as described in the previous sections using $\operatorname{PtBr}_{2}$ (46.1 $\mathrm{mg}, 0.13 \mathrm{mmol}$ ), triphenylphosphine $(34.1 \mathrm{mg}, 0.13 \mathrm{mmol})$, toluene $(5 \mathrm{~mL})$ and the appropriate amine $(45 \mathrm{mmol}$, 350 equivalents). The latter was introduced in the autoclave together with $\mathrm{PtBr}_{2}$ and $\mathrm{PPh}_{3}$ if solid $\left(\mathrm{R}=\mathrm{NO}_{2}, \mathrm{NH}_{2}, \mathrm{MeO}, \mathrm{Cl}\right.$ ), or via the septum valve by syringe if liquid. The autoclave was then charged with ethylene (25 bars) for 10 hours at $150^{\circ} \mathrm{C}$ and heated to $150^{\circ} \mathrm{C}$ for $10 \mathrm{~h}$. The workup procedure and the analysis were also identical to those described in the previous section. The TON values for the corresponding $\mathbf{1}^{\mathbf{R}}$ and $3^{\mathbf{R}}$ products were estimated on the basis of the peak integration, assuming response factors identical to that of the starting material.

\section{Results and Discussion}

\section{(a) Preliminary investigations under classical hydroamination conditions}

A first catalytic run was carried out under the optimized "Brunet" conditions except for the additional presence of one equivalent of $\mathrm{PPh}_{3}$ relative to $\mathrm{PtBr}_{2}$. The result is compared with those 
reported by Brunet with either 0 or 2 equivalents of $\mathrm{PPh}_{3}$ in Table 1 (for the compound numbering, refer to Scheme 4).

It is to be noted that the original Brunet results were obtained with a larger excess (150 equiv) of the $n \mathrm{Bu} 4 \mathrm{PBr}$ co-catalyst, ${ }^{40}$ but it has since been shown that only a 10 -fold excess of the bromide salt is sufficient to obtain the best activities while the relative amount of the $n \mathrm{Bu} 4 \mathrm{PBr}$ salt does not significantly alter the reaction selectivity. ${ }^{41}$ As show in run 3 , the activity is greatly reduced in the presence of 2 equivalents of $\mathrm{PPh}_{3}$, the TON in hydroamination product being reduced from 80 to 6 whereas the TON in quinaldine by-product remains relatively constant. The new experiment (run 2) leads to two important observations: the first one is that a significant catalytic activity is maintained, in line with the Wang and Widenhoefer observation, ${ }^{51}$ when using only 1 equivalent of $\mathrm{PPh}_{3}$, the $\mathrm{N}$-ethylaniline hydroamination product being formed with 23 cycles. The second and more unexpected result is that the production of quinaldine is greatly increased to 62 cycles, plus an additional 6 cycles of 1,2,3,4-tetrahydroquinaldine. The latter compound was also detected when using the Brunet catalytic system, although only in trace amounts. ${ }^{40}$ Therefore, the reaction selectivity is inversed by the presence of 1 equivalent of $\mathrm{PPh}_{3}$. Among the other by-products observed in trace amounts (identity confirmed by GC-MS analysis, see SI) were $\mathrm{PhNEt}_{2}$ (the product of double hydroamination), the formation of which is almost completely suppressed (0.02 cycles), and two products of hydroarylation, 2- and 4-ethylaniline ( 0.1 and 0.03 cycles, respectively). A ${ }^{1} \mathrm{H}$ NMR analysis of the gas phase after the reaction (the gases were bubbled through $\mathrm{CDCl}_{3}$ ) revealed also the formation of significant amounts of ethane $(\delta 0.88)$ together with residual ethylene $(\delta 5.43)$.

Table 1. Effect of $\mathrm{PPh}_{3}$ on the reaction between aniline and ethylene catalyzed by $\mathrm{PtBr}_{2} / \mathrm{Br}^{-}$. 


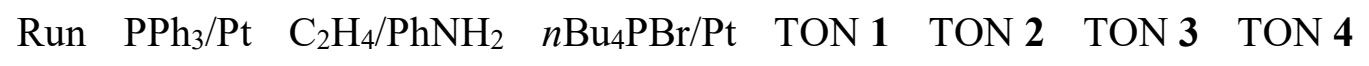

\begin{tabular}{llllllll}
\hline $1^{\mathrm{b}}$ & 0 & 2.2 & 150 & 80 & 1 & 11 & trace \\
$2^{\mathrm{c}}$ & 1 & 2.2 & 10 & 23 & 0.02 & 62 & 6 \\
$3^{\mathrm{b}}$ & 2 & 2.2 & 150 & 6 & 1 & 13 & - \\
$4^{\mathrm{d}}$ & 1 & 4.4 & 10 & 35 & - & 89 & 10 \\
5 & $1^{\mathrm{e}}$ & 2.2 & $150^{\mathrm{f}}$ & 8 & - & 14 & $<1$ \\
6 & $1^{\mathrm{e}, \mathrm{g}}$ & 2.2 & $150^{\mathrm{f}}$ & 9 & - & 12 & $<1$ \\
$7^{\mathrm{b}, \mathrm{h}}$ & 0 & 2.2 & 150 & 130 & $\mathrm{nr}$ & $\mathrm{nr}$ & $\mathrm{nr}$ \\
$8^{\mathrm{h}, \mathrm{i}}$ & 1 & 2.2 & 10 & 9 & 0.07 & 7 & 2 \\
9 & $1^{\mathrm{j}}$ & 2.2 & 10 & 1.7 & - & 1.5 & 0.1 \\
\hline
\end{tabular}

${ }^{a}$ Conditions: aniline $(4.1 \mathrm{~mL}, 45.5 \mathrm{mmol}), \mathrm{C}_{2} \mathrm{H}_{4}(25$ bar at room temperature, $100 \mathrm{mmol})$, $\mathrm{PtBr}_{2}$ (46.1 mg, $0.13 \mathrm{mmol}, 0.28 \%$ ), $150{ }^{\circ} \mathrm{C}, 10 \mathrm{~h} .{ }^{\mathrm{b}}$ Results from ref. $40{ }^{\mathrm{c}}$ Additional observed by-products: 2 -ethylaniline $(0.1$ cycle), 4 -ethylaniline ( 0.03 cycles), 2-naphthylethylamine (ca. 1 cycle). ${ }^{\mathrm{d}} \mathrm{P}\left(\mathrm{C}_{2} \mathrm{H}_{4}\right)=50$ bars, $200 \mathrm{mmol} .{ }^{\mathrm{e}} \mathrm{K}_{2} \mathrm{PtCl}_{4}$ used in place of $\mathrm{PtBr}_{2} .{ }^{\mathrm{f}} \mathrm{NaBr}$ used in place of $n \mathrm{Bu} 4 \mathrm{PBr}$, in combination with $\mathrm{H}_{2} \mathrm{O}(15 \mathrm{~mL}) .{ }^{\mathrm{g}}$ TPPTS used in place of $\mathrm{PPh}_{3} .{ }^{\mathrm{h}} \mathrm{In}$ the presence of $\mathrm{TfOH}(34 \mu \mathrm{L}, 0.39 \mathrm{mmol}) . \mathrm{nr}=$ not reported. ${ }^{\mathrm{i}}$ Additional observed by-products: 2-ethylaniline (1.7 cycle), 4-ethylaniline (ca. 1 cycle), 2-naphthylethylamine (ca. 1 cycle). ${ }^{j} \mathrm{PdBr}_{2}$ used in place of $\mathrm{PtBr}_{2}$.

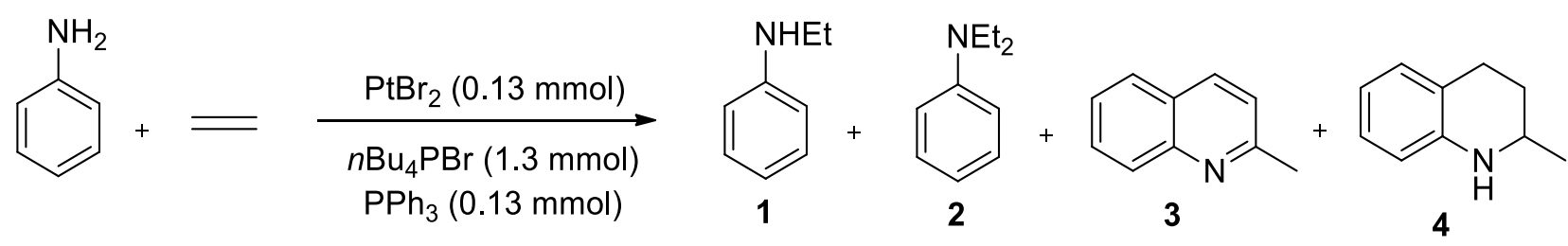

Scheme 4. Reaction of aniline and ethylene catalyzed by $\mathrm{PtBr}_{2} / 1 \mathrm{PPh}_{3} / 10 n \mathrm{Bu} 4 \mathrm{PBr}$.

As already stated in the Introduction, the literature already describes the direct transformation of aniline and ethylene into quinaldine, but the latter was rarely the major product and never produced with such high catalytic activities. For instance, 14.6 cycles were obtained with the $\mathrm{PdCl}_{2} / 2 \mathrm{PPh}_{3}$ catalyst at $200^{\circ} \mathrm{C}$ in 3 days (an average TOF of $0.2 \mathrm{~h}^{-1}$ ), ${ }^{38} v \mathrm{~s} .62$ cycles in $10 \mathrm{~h}$ at 
$150^{\circ} \mathrm{C}$ with the $\mathrm{PtBr}_{2} / 1 \mathrm{PPh}_{3} / 10 n \mathrm{Bu}_{4} \mathrm{PBr}$ catalyst described here (an average TOF of $6.2 \mathrm{~h}^{-1}$ ). It is also interesting to observe that, compared to the classical Brunet catalyst (e.g. without $\mathrm{PPh}_{3}$ ), the final reaction mixture shows essentially no deposition of metallic platinum, suggesting that the $\mathrm{PPh}_{3}$ coordination is capable of better stabilizing the $\mathrm{Pt}^{\mathrm{II}}$ center against the deactivating reduction process.

From the stoichiometric point of view, the generation of one molecule of quinaldine from one molecule of aniline and two of ethylene releases one molecule of $\mathrm{H}_{2}$ in the ring closure step to the tetrahydroquinaldine ring and two additional ones in the aromatization step. If all these $\mathrm{H}_{2}$ equivalents are captured by ethylene to generate the corresponding amount of ethane (which was indeed observed among the reaction products, vide supra), the reaction requires a global ethylene/aniline ratio of 5 (equation 1). Therefore, on the basis of the conditions used for run 2 (aniline:ethylene $=1: 2.2$ ), the maximum theoretical aniline conversion for $100 \%$ ethylene consumption would be $44 \%$. The quinaldine yield of $18.6 \%$ relative to aniline, corresponding to the 62 turnovers of run 2 , is actually $41 \%$ relative to the limiting $\mathrm{C}_{2} \mathrm{H}_{4}$ reagent. The amount of produced quinaldine is thus expected to increase upon increasing the ethylene pressure. Indeed, an increase of the ethylene pressure to 50 bars, which corresponds to a $\mathrm{PhNH}_{2} / \mathrm{C}_{2} \mathrm{H}_{4}$ ratio of 1:4.4, increased the TON of each product, see Table 1 (run 4). For practical reasons, however, all subsequent experiments were still carried out using 25 bar of ethylene pressure.

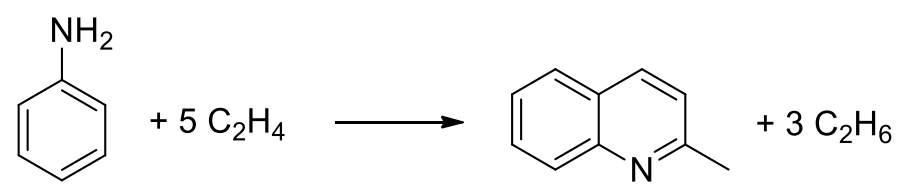


An obvious question concerning the quinaldine formation mechanism is whether the hydroamination product PhNHEt is an intermediate. The results of a catalytic run starting from $N$-ethylaniline in place of aniline under the same conditions of run 2, see Scheme 5, appear to discredit this hypothesis, because quinaldine was produced in greatly reduced amounts. This result can be rationalized as follows: while the $\mathrm{PtBr}_{2} / \mathrm{Br}^{-}$system is not efficient for the hydroamination of PhNHEt, since there are only traces of the double hydroamination product (Table 1), the aniline basicity induces partial catalyst reduction to $\mathrm{Pt}^{0},{ }^{46}$ which then catalyzes the alkyl transfer process, yielding moderate amounts of aniline and $N, N$-diethylaniline. ${ }^{44}$ Subsequently, aniline and ethylene may proceed to yield the observed small amount of quinaldine. This result appears rather insensitive to the ethylene pressure (Scheme 5).

On the basis of the recent modification of the Brunet system by $\mathrm{K}_{2} \mathrm{PtCl}_{4} / \mathrm{NaBr}_{\mathrm{aq}}$, ${ }^{42}$ we have also tested the $\mathrm{K}_{2} \mathrm{PtCl}_{4} / \mathrm{NaBr}_{\mathrm{aq}} / \mathrm{PPh}_{3}$ combination under aqueous conditions, run 5 of Table 1 . The first striking observation is that the system is ca. in 4 times less productive relative to the non aqueous system. However, quinaldine is still the major product. No significant amount of 1,2,3,4-tetrahydroquinaldine was observed in this case. Hence, although the productivity under aqueous conditions is reduced relative to the classical Brunet conditions (as also observed for the hydroamination in the absence of phosphine ${ }^{42}$ ), the effect of the $\mathrm{PPh}_{3}$ addition on the change of selectivity in favor of quinaldine remains qualitatively the same in the presence of aqueous $\mathrm{NaBr}$ as in the anhydrous medium in the presence of $n \mathrm{Bu}_{4} \mathrm{PBr}$. Substitution of $\mathrm{PPh}_{3}$ by 3,3 ',3'phosphinidynetris(benzenesulfonic acid) trisodium salt, commonly known as sodium triphenylphosphine trisulfonate (TPPTS), aiming at improving the catalyst solubility in the aqueous phase, gives essentially identical results (run 6). 


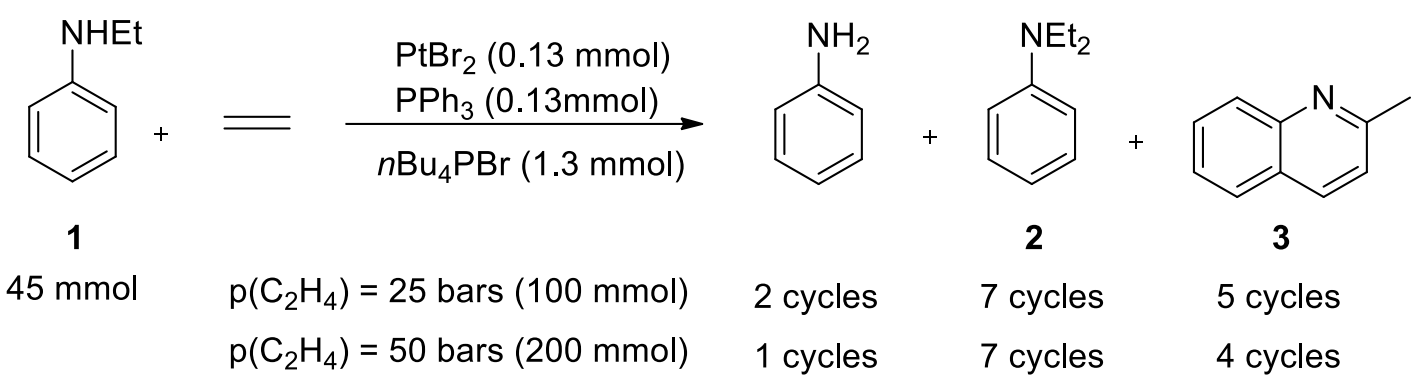

Scheme 5. Reaction between PhNHEt and $\mathrm{C}_{2} \mathrm{H}_{4}$ in the presence of $\mathrm{PtBr}_{2} / 10 \mathrm{Br}^{-} / \mathrm{PPh}_{3}$.

Since it was shown that the addition of a small amount of a strong acid (3 equiv of TfOH relative to $\mathrm{PtBr}_{2}$ ) to the Brunet catalyst has a positive effect on the hydroamination reaction, $c f$. run 7 and run $1,{ }^{40}$ we have tested the same effect of the $\mathrm{PPh}_{3}$-modified catalyst. The results of this test (run 8) clearly shown that in this case the acid addition has a negative effect on both hydroamination and quinaldine formation processes, whereas the formation of the minor hydroarylation products was substantially increased (2-ethylaniline: from 0.01 to 1.7 cycles; 4 ethylaniline: from 0.03 to ca. 1 cycle). The yield reduction on the hydroamination product was quite unexpected, because the strong acid should in principle be quenched by the strongest base available (aniline at the beginning, PhNHEt after the initial hydroamination) to yield the corresponding amount of ammoniums salts, while $\mathrm{PPh}_{3}$ should remain available to coordinate $\mathrm{Pt}^{\mathrm{II}}$. While the beneficial effect of the strong acid on the $N$-ethylaniline formation ( $c f$. run 1 and run 7) is reversed by the presence of $\mathrm{PPh}_{3}$ (cf. run 2 and run 8), the combined acid/ $\mathrm{PPh}_{3}$ presence also negatively affects the quinaldine formation ( $c f$. run 1 and run 8 ). The final entry in Table 1 (run 9) shows that $\mathrm{PdBr}_{2}$ is much poorer than $\mathrm{PtBr}_{2}$ as a catalyst for quinaldine formation in the presence of $\mathrm{PPh}_{3}$, as was already shown for hydroamination in the absence of $\mathrm{PPh}_{3}$.

\section{(b) Study of the influence of the halide in the additive and in the catalyst}


By analogy with the hydroamination condition optimization, where the best $n$-butylammonium salt co-catalyst resulted to be the bromide salt when used in moderate excess amounts (10 equivalents), ${ }^{41}$ we carried out additional investigations on the effect of the nature and amount of halide salt additive in the presence of $\mathrm{PPh}_{3}(\mathrm{P} / \mathrm{Pt}=1)$ on the quinaldine formation. The results are presented in Table 2 .

The general observation is that the TON obtained with the chloride and iodide salt is marginally lower than the TON obtained with the equivalent amount of bromide (for the result with 10 equivalents of $\mathrm{Bu} 4 \mathrm{PBr}$, see run 2 in Table 1). The catalyst efficiency decreases upon increasing the amount of salt in the medium, again in a way that is little sensitive to the nature of the halide. The amount of N-ethylaniline, the secondary product in these experiments, equally decreases upon increasing the amount of salt, but the ratio of the two products does not remain constant, further supporting the notion that they result from different mechanistic pathways. The amount of the other by-product, the tetrahydroquinaldine, always remains quite low. Run 17 shows the result of a control experiment, carried out in the absence of tetra- $n$-butylphosphonium salt. The quinaldine formation increased to 61 cycles, indicating that the presence of the salt additive is not beneficial for the quinaldine synthesis, contrary to the effect (in the absence of $\left.\mathrm{PPh}_{3}\right)$ to the hydroamination process.

Table 2. Influence of the $n \mathrm{Bu} 4 \mathrm{PX}$ additive on the quinaldine formation. ${ }^{\mathrm{a}}$

\begin{tabular}{llllll} 
Run & Salt & $\mathrm{X} / \mathrm{Pt}$ & TON 1 & TON 3 & TON 4 \\
\hline 10 & $\mathrm{Bu} 4 \mathrm{PBr}$ & 65 & 9 & 33 & 3 \\
11 & $\mathrm{Bu}{ }_{4} \mathrm{PBr}$ & 150 & 8 & 28 & 3 \\
\hline 12 & $\mathrm{Bu} 4 \mathrm{PCl}$ & 10 & 13 & 39 & 2
\end{tabular}




\begin{tabular}{llllll}
13 & $\mathrm{Bu}_{4} \mathrm{PCl}$ & 65 & 4 & 12 & 1 \\
\hline 14 & $\mathrm{Bu} 4 \mathrm{PI}$ & 10 & 16 & 41 & 4 \\
15 & $\mathrm{Bu} 4 \mathrm{PI}$ & 65 & 10 & 23 & 2 \\
16 & $\mathrm{Bu} 4 \mathrm{PI}(150)$ & 150 & 4 & 9 & 1 \\
\hline 17 & - & & 18 & 61 & 3 \\
$18^{\mathrm{b}}$ & - & 22 & 66 & 4 \\
\hline
\end{tabular}

a The conditions were identical to those used in Table 1 (footnote $a$ ). ${ }^{\mathrm{b}}$ Reaction time: $65 \mathrm{~h}$.

The results of run 18 correspond to an experiment identical to run 17, except for a reaction time of $65 \mathrm{~h}$ instead of 10 . The yields of both major products remain essentially the same, although large amounts of both the aniline and ethylene reagents (conversions of ca. 27\% and $61 \%$, the latter based on the theoretical stoichiometry of equation 1) are still present in the autoclave. This comparison suggests that the catalyst is no longer active after 10 hours of operation. At the end of these experiments, as for those outlined in Table 1, no significant metallic platinum deposit was observed in the autoclave, confirming that $\mathrm{PPh}_{3}$ protects the catalyst system from the reductive deactivation process. However, the catalyst must slowly transform into a catalytically inactive species during the reaction, which probably corresponds to the orange precipitate observed in the recovered reaction mixture at the end of the catalytic run. Our efforts aimed at characterizing this species have not yet been successful. The product of double hydroamination $\mathbf{2}$, not reported in Table 2 , has always been detected in trace amounts $(<$ 1 cycle), in line with the results shown in the previous section (Table 1). All subsequent experiments have therefore been carried out without the tetra- $n$-butylammonium salt additive.

We have then investigated the effect of the halide nature on the $\mathrm{PtX}_{2}$ salt. The results, $c f$. runs 19 and 20 in Table 3 with run 17 in Table 2, seem to indicate that this parameter does not strongly affect the catalytic activity. On the basis of the literature knowledge, it seems likely that 
the addition of $\mathrm{PPh}_{3}$ under the catalytic conditions gives rise to the formation of a complex of type $\left[\mathrm{PtBr}_{2}\left(\mathrm{PPh}_{3}\right) \mathrm{L}\right]$, where $\mathrm{L}$ is either ethylene or aniline. The chlorido complex $\left[\mathrm{PtCl}_{2}\left(\mathrm{PPh}_{3}\right)\left(\mathrm{C}_{2} \mathrm{H}_{4}\right)\right]$ with a cis stoichiometry is known. ${ }^{54,55}$ Bromide analogues are also known, although with other phosphines,${ }^{54}$ and iodide derivatives have equally been described where the olefin and phosphine donors are part of the same bidentate ligand. ${ }^{56-58}$ For practical convenience, the rest of this study was pursued using $\mathrm{PtBr}_{2}$ as pre-catalyst.

Table 3. Influence of the halide in the $\mathrm{PtX}_{2}$ catalyst on the quinaldine formation. ${ }^{\mathrm{a}}$

\begin{tabular}{lllll} 
Run & $\mathrm{PtX}_{2}$ & TON 1 & TON 3 & TON 4 \\
\hline 19 & $\mathrm{PtCl}_{2}$ & 12 & 55 & 1 \\
20 & $\mathrm{PtI}_{2}$ & 28 & 49 & 4
\end{tabular}

${ }^{a}$ Conditions: aniline $(4.1 \mathrm{~mL}, 45.5 \mathrm{mmol}), \mathrm{C}_{2} \mathrm{H}_{4}(25$ bars at room temperature, $100 \mathrm{mmol})$, $\mathrm{PtX}_{2}(0.13 \mathrm{mmol}), \mathrm{PPh}_{3}(34.1 \mathrm{mg}, 0.13 \mathrm{mmol}), 150{ }^{\circ} \mathrm{C}, 10 \mathrm{~h}$.

\section{(c) Kinetic profile}

With the purpose of learning more about the catalyst decomposition process, we wished to run additional catalytic experiments with sample withdrawal and conversion monitoring. In order for this to be done, the catalytic conditions had to be slightly modified, notably the volume of the liquid phase had to be increased, in order to allow the withdrawal of a sufficient number of samples during the run, with all appropriate care to allow for siphon washing to eliminate contamination of a given sample by the residues of the previous one. A preliminary study of the effect of the dilution by an inert solvent gave the results reported in Table 4 .

Table 4. Influence of dilution and solvent nature on the quinaldine formation. ${ }^{\mathrm{a}}$ 


\begin{tabular}{llclll} 
Run & Solvent & Amount $/ \mathrm{mL}$ & TON 1 & TON 3 & TON 4 \\
\hline 21 & toluene & 5 & 20 & 77 & 2 \\
22 & THF & 5 & 25 & 83 & 3 \\
23 & toluene & 15 & 6 & 10 & 0 \\
$24^{\mathrm{b}}$ & toluene & 5 & 20 & 86 & 3 \\
$25^{\mathrm{b}}$ & c & - & 20 & 79 & 2 \\
26 & $\mathrm{NEt}_{3}$ & 5 & 5 & 5 & 0
\end{tabular}

${ }^{\mathrm{a}}$ The conditions were identical to those used in Table 1 (footnote $a$ ). ${ }^{\mathrm{b}} 19 \mathrm{~h} .{ }^{\mathrm{c}} 8.2 \mathrm{~mL}$ aniline (91 mmol).

Rather unexpectedly, dilution with a small amount ( $5 \mathrm{~mL}$ ) of toluene or THF (runs 21 and 22) resulted in even greater yields than the equivalent experiment carried out without dilution (run 17 of Table 2). On the other hand, a greater extent of dilution ( $15 \mathrm{~mL}$ of toluene, run 23 ) decreases the activity as expected. The initial activity increase may be related to a greater ability of the solvent in the initial disaggregation of the tridimensional $\mathrm{PtBr}_{2}$ network facilitating the formation of the active soluble catalyst, or to a genuine solvent effect on the catalytic cycle energetic span (for instance a stabilization of the rate-determining transition state). Running the reaction for a longer time (19 h, run 24) resulted in a barely greater yield, confirming the catalyst deactivation already noted above. Interestingly, a similar yield was also observed when the dilution was accomplished by addition of a greater amount of aniline (run 25). This result would tend to discredit the idea of a solvent effect on the energy span. ${ }^{59}$ When the dilution was accomplished by addition of a stronger Brønsted base ( $\mathrm{NEt}_{3}$, run 26), on the other hand, the activity was greatly reduced. This effect is reminiscent of the negative effect of Brønsted basicity on the catalyst lifetime (deactivation by reduction to metallic Pt) ${ }^{44}$ However, in the present case no black 
precipitated was noted. Instead, the reaction mixture appeared as a brown solution giving a brown precipitate upon work-up (addition of diethyl ether).

Given that the catalytic system does not suffer (on the contrary, it is slightly aided) by a small dilution, we have proceeded to study the reaction profile under the optimized conditions of runs 21 and 24. This gave the results illustrated in Figure 1. The first immediate observation is the confirmation of the catalyst deactivation, the yield of both major products $\mathbf{1}$ and $\mathbf{3}$ stagnating after approximately ca. 5-7 hours of operation, when the aniline conversion is still $<30 \%$. The profile also clearly indicates the presence of an induction period, greater than $15 \mathrm{~min}$, for both independent transformations. It is interesting to note that a previous kinetic study of the hydroamination catalyst $\left(\mathrm{PtBr}_{2} / n \mathrm{Bu}_{4} \mathrm{PX}, \mathrm{X}=\mathrm{Cl}, \mathrm{Br}, \mathrm{I}\right)^{45}$ had revealed a much shorter induction period, with 11 cycles already accomplished after 15 min for the most active $\mathrm{Br}^{-}$system. Thus, it seems that the bromide salt is more efficient than $\mathrm{PPh}_{3}$ for converting the insoluble $\mathrm{PtBr}_{2}$ precatalyst into the soluble catalytically active species.

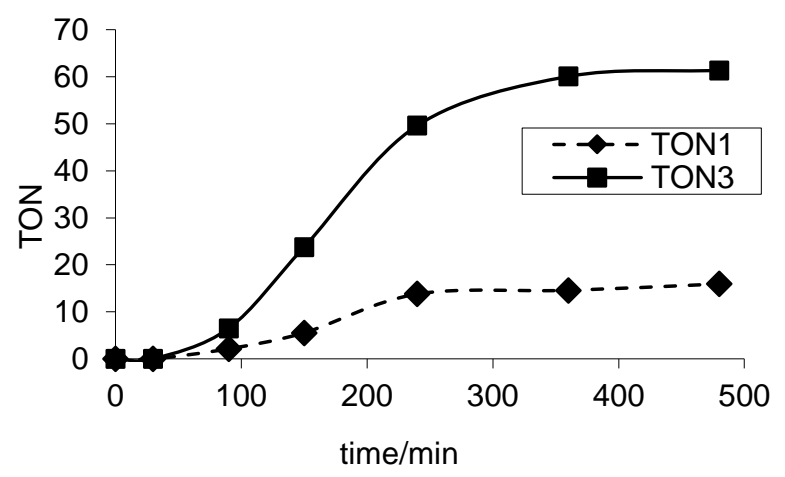

Figure 1. Kinetic profile of the quinaldine formation with the $\mathrm{PtBr}_{2} / \mathrm{PPh}_{3}$ catalytic system. The reaction conditions are identical to those of run 21 in Table 4.

\section{(d) Effect of the phosphine ligand}


Once the presence of activating halide salts was proven unnecessary for the heterocyclization catalytic cycle leading to quinaldine formation, we have decided to revisit the effect of the $\mathrm{P} / \mathrm{Pt}$ ratio under halide-free conditions varying this ratio in steps of 0.5 units between zero and two. The results are shown in Table 5. The results of runs 27, taken from the previous study, ${ }^{40}$ are different from those of run 1 of Table 1 since no halide co-catalyst is used here. For the same reason, result of run 31 differs from the previously published result,${ }^{40}$ where only 2 cycles where reported for both 1 and 3, 1 for 2, and no formation of $\mathbf{4}$ was mentioned. Thus, $\mathrm{PPh}_{3}(2$ equivalents) exert a stronger inhibition of both hydroamination and quinaldine formation in the presence of a large excess (150 equiv) of bromide salt.

Table 5. Influence of the amount of $\mathrm{PPh}_{3}$ on the quinaldine formation. ${ }^{\mathrm{a}}$

\begin{tabular}{llllll} 
Run & $\mathrm{PPh}_{3} / \mathrm{Pt}$ & TON 1 & TON 2 & TON 3 & TON 4 \\
\hline $27^{\mathrm{b}}$ & 0 & 23 & 1 & 3 & n.r. \\
28 & 0.5 & 17 & 0 & 66 & 2 \\
29 & 1 & 20 & 0 & 77 & 2 \\
30 & 1.5 & 36 & 0 & 69 & 3 \\
31 & 2 & 27 & 1 & 39 & 3
\end{tabular}

${ }^{a}$ The conditions were identical to those used in run 21 of Table 4 except for the amount of $\mathrm{PPh}_{3 .}{ }^{\mathrm{b}}$ Results from reference 40 (n.r. $=$ not reported).

The influence of the $\mathrm{PPh}_{3}$ amount is striking, with a small proportion of 0.5 equivalents being already sufficient to boost the formation of quinaldine and to completely change the catalyst selectivity (cf. run 27 and 28). On going from 0.5 to 1.5 equivalents per Pt atom (runs 28-30), the quinaldine yield remains high, although it is maximum for a $\mathrm{P} / \mathrm{Pt}$ ratio of 1 . Upon reaching a ratio of 2, on the other hand, the activity falls sharply (run 32), being reduced to one half of that 
obtained with 1.5 equivalent. The formation of $N$-ethylaniline, on the other hand, seems less affected by the $\mathrm{P} / \mathrm{Pt}$ increase. We can reasonably anticipate that the introduction of two equivalents of $\mathrm{PPh}_{3}$ induces the formation of $\mathrm{PtBr}_{2}\left(\mathrm{PPh}_{3}\right)_{2}{ }^{60}$ with relatively robust $\mathrm{Pt}-\mathrm{P}$ bonds, rendering the Pt coordination sites less accessible for the catalytic transformation.

After confirming that the best $\mathrm{P} / \mathrm{Pt}$ ratio for the quinaldine formation is 1 , we have also investigated the effect of the phosphine nature. For this purpose, we have chosen to restrict the study to the $\mathrm{PMe}_{\mathrm{x}} \mathrm{Ph}_{3-\mathrm{x}}$ series smoothly going from a triaryl $(\mathrm{x}=0)$ to a trialkyl $(\mathrm{x}=3)$ phosphine. The results are shown in Table 6. These runs were carried out without toluene dilution. Therefore, the results should be compared with that of the experiment with $\mathrm{PPh}_{3}$ of run 17 in Table 2. In order to verify the reproducibility of the results and in particular because of the technical difficulty of introducing small amounts of the liquid phosphines in the autoclave, each run was repeated; the table contains the average values and the differences between the two runs.

The best results are those obtained in the presence of $\mathrm{PPh}_{3}$, followed by those with $\mathrm{PMePh}_{2}$ (run 32). For unknown reasons, the trend is not monotonous, since $\mathrm{PMe}_{2} \mathrm{Ph}$ (run 33) gives a lower TON for quinaldine relative to $\mathrm{PMe}_{3}$ (run 34) while, at the same time, this ligand also gives a greater TON for $N$-ethylaniline relative to all other phosphines. Therefore, the presence of aromatic substituents on the phosphorus atom seems important to maximize quinaldine formation.

Table 6. Influence of the phosphine nature on the quinaldine formation. ${ }^{\mathrm{a}}$

\begin{tabular}{lllll} 
Run & Phosphine & TON 1 & TON 3 & TON 4 \\
\hline 32 & $\mathrm{PMePh}_{2}$ & $16 \pm 1$ & $44 \pm 6$ & $4 \pm 1$ \\
33 & $\mathrm{PMe} 2 \mathrm{Ph}$ & $26 \pm 6$ & $5 \pm 1$ & $<1$
\end{tabular}


${ }^{\text {a }}$ The conditions were identical to those used in Table 3 (footnote $a$ ).

\section{(e) Influence of aniline para substituents.}

In order to briefly evaluate the potential generality of this reaction, we have carried out a small scope study on $p$-substituted anilines, with the substituent nature covering a range of donor and acceptor groups. The reaction gives rise to the formation of $N$-ethtyl-4-R-aniline $\left(\mathbf{1}^{\mathbf{R}}\right)$ and 2 methyl-6-R-quinoline $\left(3^{\mathbf{R}}\right)$ as main products from the hydroamination and cyclization processes, respectively, see Scheme 6. The catalytic results are collected in Table 7. The reactions were carried out under the conditions previously optimized for aniline, namely in the presence of 1 equiv of $\mathrm{PPh}_{3}$, in the absence of additional halide salts, and with dilution by $5 \mathrm{~mL}$ of toluene. It is to be noted that certain substituted anilines are solid at room temperature but melt at a temperature lower than that used for the reaction.
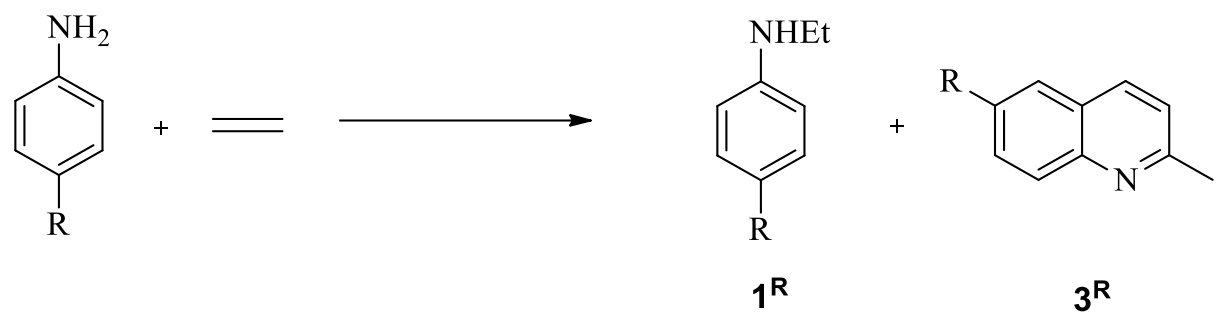

Scheme 6. General scheme of the reaction between $p$-substituted aniline and ethylene catalyzed by $\mathrm{PtBr}_{2} / \mathrm{PPh}_{3}$.

Table 7. Influence of the para-substituent $\mathrm{R}$ on aniline on the quinoline formation and on hydroamination. ${ }^{a}$

Run $\mathrm{R} \quad \mathrm{pK}_{\mathrm{a}}^{\mathrm{b}} \quad$ TON $\mathbf{1}^{\mathrm{R}} \quad \mathrm{TON}^{\mathrm{Rc}}$




$\begin{array}{lllll}35 & \mathrm{NO}_{2} & 0.98 ; 1.11 & 22 & <1 \\ 36 & \mathrm{Cl} & 3.81 & 35 & 85 \\ 37^{\mathrm{d}} & n \mathrm{Bu} & 4.91 & 34 & 81 \\ 38 & \mathrm{CH}_{3} \mathrm{O} & 5.29 & 39 & 66 \\ 39 & \mathrm{NEt}_{2} & 8.21 & 9 & 14\end{array}$

\begin{abstract}
${ }^{a}$ The conditions were identical to those used in run 22 of Table $4 .{ }^{b}$ Acid dissociation constant of the conjugated anilinium ion. Values from http://research.chem.psu.edu/brpgroup/pKa_compilation.pdf. ${ }^{\mathrm{c}}$ For all quinoline derivatives, except $\mathrm{R}=\mathrm{NEt}_{2}$ for which the peak identity was confirmed by GC of the isolated pure products, the peak was attributed on the basis of the retention time; the MS study of the mixture confirmed the presence of $3^{\mathbf{R}}$ in substantial amounts (MS spectra in SI). ${ }^{\mathrm{d}}$ Run carried out in the absence of toluene.
\end{abstract}

The TON values reported in Table 7 for all complexes, except for $\mathrm{R}=\mathrm{NEt}_{2}$, are to be considered as rough estimations, limiting a fine comparison of activities, because genuine and pure samples of the products $\mathbf{1}^{\mathbf{R}}$ and $\mathbf{3}^{\mathbf{R}}$ for the GC calibration were not available. Although all the produced N-ethylaniline $e^{61-65}$ and quinoline $e^{53,66-69}$ derivatives are known in the literature, many of them are not commercially available. However, considering that the response coefficients should not be dramatically dependent on the nature of $\mathrm{R}$, indicative trends may be extracted from the data. In particular, it is immediately obvious that the presence of the $p-\mathrm{R}$ substituent has a profound effect on the catalytic activity, especially for the formation of the quinoline product $3^{\mathbf{R}}$ which remains the major product in all cases except for the $p$-nitroaniline substrate (run 35). The yield of substituted quinoline does not appear to correlate with the aniline basicity, since both the least and most basic anilines give the poorest results (runs 35 and 39), whereas the best results are obtained for anilines of intermediate basicity, the best corresponding to the unsubstituted aniline (run 21 of Table $4, \mathrm{pK}_{\mathrm{a}}=4.61$ ). Aniline of similar basicity (the $p$-Cl and $p-n \mathrm{Bu}$, runs 36 and 37 ) give rise to similar yields for the corresponding substituted 
quinoline, whereas introduction of the $\pi$-donating $\mathrm{MeO}$ substituent (run 38) seems to negatively affect the cyclization process, although as stated above not much emphasis can be put on this comparison. The lack of a clear effect of basicity is in contrast with the results presented for the hydroamination process with the $\mathrm{PtBr}_{2} / n \mathrm{Bu}_{4} \mathrm{PBr}$ catalyst, ${ }^{40}$ as well for other hydroamination catalysts, ${ }^{70}$ where the activity correlates with the aniline basicity, better results being obtained for less basic substrates. It has been suggested, however, that this phenomenon may simply be related to faster catalyst decomposition to metallic $\mathrm{Pt}$ in the presence of a more basic environment. In the present case, the effect of $\mathrm{PPh}_{3}$ is to practically eliminate the reduction process to $\mathrm{Pt}^{0}$, but a catalyst deactivation is still observed (see section $c$ ). In the absence of a clear understanding of the nature of this decomposition product and of the mechanism leading to it, it is not possible to speculate on the exact reason for the activity trend shown in Table 7.

\section{(f) Mechanistic considerations.}

The evidence collected during the present study, in addition to our recently improved mechanistic knowledge of the hydroamination catalytic cycle based on this catalytic system ${ }^{71}$ and of the catalyst decomposition pathway, ${ }^{46}$ allows the addition of a few considerations to the quinaldine formation mechanism. The essential features of the hydroamination catalytic cycle are recalled in Scheme $7 .{ }^{71}$ They involve the ethylene complex $\mathbf{A}(\mathrm{L}=\mathrm{Br})$ as the resting state, the zwitterionic intermediate $\mathbf{B}$, which transfers a proton from the ammonium group to the metal to yield the 5-coordinated 16-electron $\mathrm{Pt}^{\mathrm{IV}}$ hydride intermediate $\mathbf{C}$, followed by $\mathrm{C}-\mathrm{H}$ reductive elimination (rate determining step) to the $\sigma$-complex $\mathbf{D}$ and final product expulsion to regenerate A by ethylene coordination. As argued by Brunet ${ }^{72}$ the promoting effect of the bromide ion for the PhNHEt production consists in facilitating the rate determining step by lowering the energy 
of intermediate $\mathbf{C}$, since the negatively charged $\mathrm{Br}^{-}$ligand can better stabilize the unsaturated configuration of this intermediate and of the subsequent rate-determining transition state.

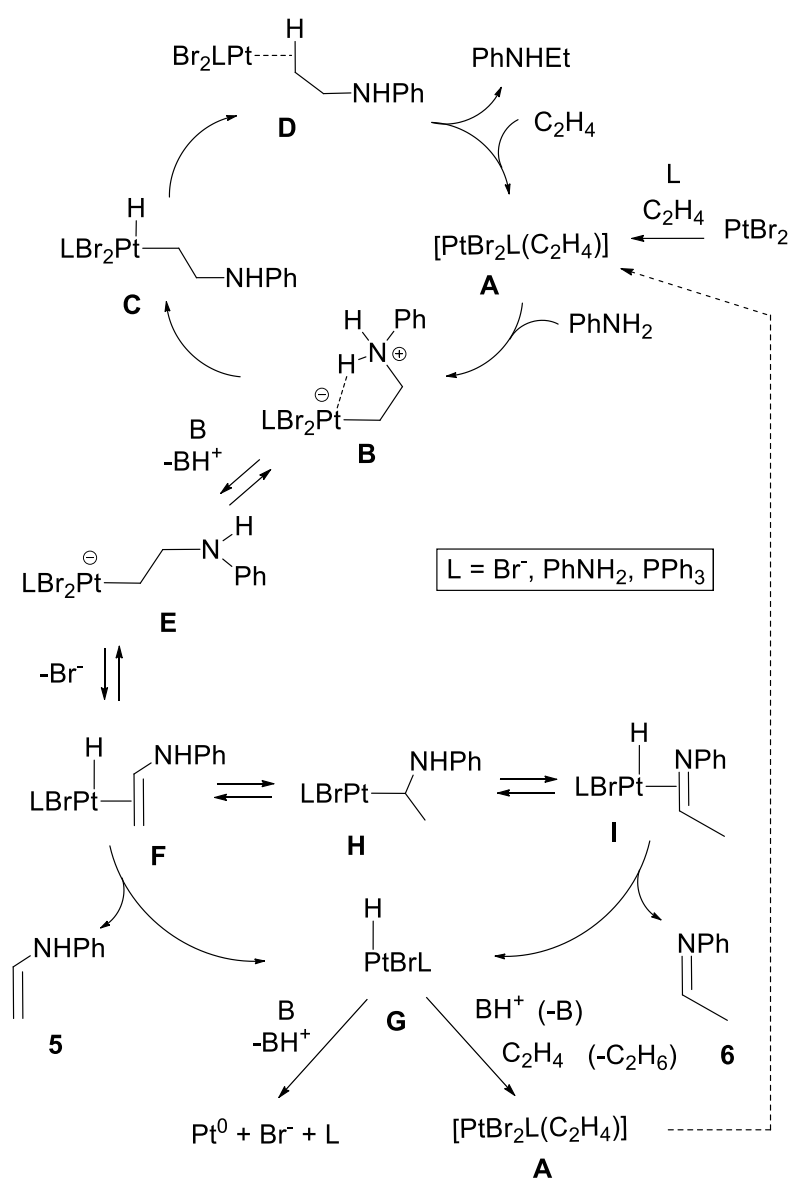

Scheme 7. Proposed mechanism for the effect of $\mathrm{L}\left(\mathrm{Br}^{-}, \mathrm{PhNH}_{2}, \mathrm{PPh}_{3}\right)$ on the metal-catalyzed quinoline skeleton formation $v s$. hydroamination.

As established in our recent investigation of the catalyst decomposition, ${ }^{46}$ the pathway leading to the formation of $\mathrm{Pt}^{0}$ involves a $\beta-\mathrm{H}$ elimination step from the zwitterionic intermediate $\mathbf{B}$ to yield a coordinated enamine ligand in complex $\mathbf{F}$ via the aminoalkyl intermediate $\mathbf{E}$ (see Scheme 7). Then, catalyst deactivation can be easily envisaged as involving enamine dissociation leading 
to the 14-electron hydride intermediate $\mathbf{G}$, followed by further deprotonation. The presence of a strong external Brønsted base, known to rapidly deactivate the $\mathrm{PtBr}_{2} / \mathrm{Br}^{-}$catalyst by reduction to $\mathrm{Pt}^{0},{ }^{44,45}$ would favor choosing this path at the crossroad $\mathbf{B}$. The pathway leading to quinaldine, as shown in Scheme 3, requires the formation of the enamine 5 and its imine tautomer $\mathbf{6}$. They can both be imagined as emanating from intermediate $\mathbf{F}$, since two steps of reinsertion and $\beta$-H elimination lead to the imine complex I through the aminoalkyl intermediate $\mathbf{H}$. Closing the catalytic cycle for quinaldine formation requires catalyst regeneration from the hydride intermediate $\mathbf{G}$, instead of reductive deactivation. This is possible by hydride transfer to an acceptor, such as ethylene to yield ethane, but also the dihydroquinaldine 9 to yield the observed tetrahedroquinaldine 4 , with assistance by the protons that have been generated in a previous step, as shown in Scheme 7. This reactivation is closely related to the mechanism proposed by Beller et al. for the Rh-catalyzed oxidative amination of aromatic olefins. ${ }^{73,74}$ Hence, the quinaldine formation mechanism and the catalyst decomposition pathway are intimately linked to each other.

The global mechanistic scheme that we propose has two crossroads at intermediates $\mathbf{B}$ and $\mathbf{G}$. If $\mathrm{L}=\mathrm{Br}^{-}$and no strong base is present, the hydroamination path is the favored one at crossroad B, while quinaldine formation with catalyst regeneration is favored at crossroad $\mathbf{G}$. However, slow catalyst decomposition occurs by occasional deprotonation of $\mathbf{G}$ by aniline, a weak Brønsted base, and the presence of a strong acid retards this decomposition process by producing the $\mathrm{PhNH}_{2} / \mathrm{PhNH}_{3}{ }^{+}$buffer and a consequent slight $\mathrm{pH}$ reduction. When a stronger Brønsted base is present, the deprotonation processes are favored at both crossroads, leading to rapid catalyst deactivation. In the presence of $\mathrm{PPh}_{3}$, on the other hand, the $\beta-\mathrm{H}$ elimination pathway at crossroad B becomes preferred, leading to a change of selectivity in favor of quinaldine 
formation. This probably results from an increase of the rate determining transition state barrier of the hydroamination cycle. On, the other hand, intermediate $\mathbf{G}$ is protected against deprotonation by the electronic effect of the softer phosphine ligand, directing the system toward catalyst regeneration.

The negative effect of halide salt additives on the catalytic activity (in the presence of $\mathrm{PPh}_{3}$ ) can be easily rationalized on the basis of a competition with ethylene for the platinum coordination site on going from $\mathbf{G}$ to $\mathbf{A}$, whereas in the absence of $\mathrm{PPh}_{3}$ the coordination of ethylene to " $\mathrm{PtBr}_{3}^{-}$" to yield $\left[\mathrm{PtBr}_{3}\left(\mathrm{C}_{2} \mathrm{H}_{4}\right)\right]^{-}$is energetically favored over coordination of $\mathrm{Br}^{-}$to yield $\left[\mathrm{PtBr}_{4}\right]^{2-} \cdot{ }^{75}$ When a greater amount of $\mathrm{PPh}_{3}$ is present $(\mathrm{P} / \mathrm{Pt}$ ratio $>1)$, this ligand enters in competition with the olefin for coordination, leading to $\mathrm{PtBr}_{2}\left(\mathrm{PPh}_{3}\right)_{2}{ }^{60}$ and therefore hampers the catalyst ability to coordinate and activate the olefin substrate.

A couple of observations remain without rationalization. One is the negative effect of acidity on the quinaldine formation in the presence of 1 equivalent of $\mathrm{PPh}_{3}$. Since acidity has no negative effect on the hydroamination cycle ${ }^{40}$ and should have a positive effect on the catalyst regeneration step (G to $\mathbf{A}$ in Scheme 7) in the heterocyclization cycle, it is conceivable that it will negatively affect the follow up process leading from the enamine and imine intermediates 5 and 6 to quinaldine (Scheme 3). Note that the formation of the quinaldine by-product during the hydroamination catalytic run in the presence of $\mathrm{TfOH}$ and absence of $\mathrm{PPh}_{3}$ (run 7 in Table 1) was not reported, hinting to a negative effect of acidity independently on the $\mathrm{PPh}_{3}$ presence. It is also not clear at this point whether the heterocyclization process from $\mathbf{5}$ and $\mathbf{6}$ is metal catalyzed or not. Another obscure feature is the pathway to catalyst deactivation when $\mathrm{PPh}_{3}$ is present, which does not involve reduction to $\mathrm{Pt}^{0}$. The isolation and characterization of the spent catalyst, to be attempted in future investigations, will hopefully clarify this point. 


\section{Conclusion.}

We have reported here the peculiar effect of the addition of $\mathrm{PPh}_{3}(1 \mathrm{P} / \mathrm{Pt})$ to the Brunet catalyst in terms of the selectivity for the reaction between aniline and ethylene, in favor of the formation of quinaldine. Optimization of the reaction has show that, contrary to the hydroamination process, the addition of the halide salts $n \mathrm{Bu}_{4} \mathrm{PX}(\mathrm{X}=\mathrm{Cl}, \mathrm{Br}, \mathrm{I})$ does not have a positive effect on the catalytic activity. The optimum amount and type of the phosphine ligand is one equivalent of $\mathrm{PPh}_{3}$, the presence of a high number of aryl substituents being beneficial to the reaction. A small degree of dilution of the medium has allowed an increase of the TON, even though the reason for this phenomenon is not completely clear. The presence of an induction time at the beginning of the reaction would seem to suggest that a long period is necessary to break the tridimensional nature of the $\mathrm{PtBr}_{2}$ catalyst to generate the active soluble catalyst. Although the presence of $\mathrm{PPh}_{3}$ protects the platinum system from reduction to the metallic state, the catalyst is still deactivated by an unknown pathway. Finally, a small scope study has shown the applicability of this reaction to other para substituted anilines, but the best activity remains associated with the parent aniline substrate and the activity does not correlate with the aniline basicity. Mechanistic considerations have been advanced with proposition of a global scheme where the hydroamination cycle, the quinaldine formation cycle, and the reductive deactivation process are interconnected through two crossroads represented by two key intermediates, a $\mathrm{Pt}^{\mathrm{II}}$ zwitterionic complex and a $\mathrm{Pt}^{\mathrm{II}}$ hydride complex. This scheme, however, still requires fine tuning, notably in terms of the yet unknown non reductive catalyst decomposition pathway, before full understanding of this complex catalytic system can be claimed and used to develop new efficient and hopefully robust catalysts for either the hydroamination or the quinoline formation. 


\section{AUTHOR INFORMATION}

\section{Corresponding Author}

*Rinaldo Poli. LCC (Laboratoire de Chimie de Coordination), 205 route de Narbonne, BP 44099, F-31077 Toulouse Cedex 4, France. Tel +33-561333173. Fax +33-561553003. Email: rinaldo.poli@1cc-toulouse.fr.

\section{Author Contributions}

The manuscript was written through contributions of all authors. All authors have given approval to the final version of the manuscript.

\section{ACKNOWLEDGMENT}

We are grateful to the Centre National de la Recherche Scientifique (CNRS), the Institut Universitaire de France (IUF), and the Agence Nationale de la Recherche (ANR, Grant «HYDROAM » No. NT09_442499) for financial support. 


\section{REFERENCES.}

(1) Gildchrist, T. L. Heterocyclic Chemistry; Pitman Publishing LTD: London, 1985.

(2) Tietze, L. F.; Ma, L. Heterocycles 2010, 82, 377-396.

(3) Mekheimer, R. A.; Ahmed, E. A.; Sadek, K. U. Tetrahedron 2012, 68, 1637-1667.

(4) Rebstock, A. S.; Mongin, F.; Trecourt, F.; Queguiner, G. Organic \& Biomolecular Chemistry 2004, 2, 291-295.

(5) Ahmad, M.; Rizvi, S. U. F.; Siddiqui, H. L.; Ahmad, S.; Parvez, M.; Suliman, R. Medicinal Chemistry Research 2012, 21, 2340-2348.

(6) Muruganantham, N.; Sivakumar, R.; Anbalagan, N.; Gunasekaran, V.; Leonard, J. T. Biological \& Pharmaceutical Bulletin 2004, 27, 1683-1687.

(7) Li, S. Y.; Guo, C. Y.; Sun, X. Q.; Li, Y. Z.; Zhao, H. L.; Zhan, D. M.; Lan, M. B.; Tang, Y. European Journal of Medicinal Chemistry 2012, 49, 271-278.

(8) Tolkki, A.; Kaunisto, K.; Heiskanen, J. P.; Omar, W. a. E.; Huttunen, K.; Lehtimaki, S.; Hormi, O. E. O.; Lemmetyinen, H. Thin Solid Films 2012, 520, 4475-4481.

(9) Goel, A.; Kumar, V.; Singh, S. P.; Sharma, A.; Prakash, S.; Singh, C.; Anand, R. S. Journal of Materials Chemistry 2012, 22, 14880-14888.

(10) Maiti, J.; Srivastava, R.; Kamalasanan, M. N.; Dolui, S. K. POLYMER INTERNATIONAL 2011, 60, 1030-1038.

(11) Yanar, M.; Genc, E. R. Turk. J. Vet. Anim. Sci. 2004, 28, 1001-1005.

(12) Huang, L. A.; Chen, F. J.; Xi, P. X.; Xie, G. Q.; Li, Z. P.; Shi, Y. J.; Xu, M.; Liu, H. Y.; Ma, Z. R.; Bai, D. C.; Zeng, Z. Z. Dyes and Pigments 2011, 90, 265-268.

(13) Jyothish, K.; Avirah, R. R.; Ramaiah, D. Org. Lett. 2006, 8, 111-114.

(14) Jyothish, K.; Avirah, R. R.; Ramaiah, D. Arkivoc 2007, 296-310.

(15) Avirah, R. R.; Jyothish, K.; Ramaiah, D. J. Org. Chem. 2008, 73, 274-279.

(16) Manske, R. H. Chem. Rev. 1942, 30, 113-144.

(17) Franklin, E. C.; Bergstrom, F. W. Chem. Rev. 1944, 35, 77-277.

(18) Gilchrist, T. L. Heterocyclic chemistry, 3rd ed.; Prentice Hall, 1997.

(19) Skraup, Z. H. Monatsh. Chem. 1881, 2, 587-609.

(20) Doebner, O.; Miller, W. V. Ber. Dtsch. Chem. Ges. 1881, 14, 2812-2817.

(21) Pfitzinger, W. J. Prakt. Chem. 1886, 33, 100.

(22) Limpach, L. Ber. Dtsch. Chem. Ges. 1931, 64, 970-971.

(23) Friedländer, P. Ber. Dtsch. Chem. Ges. 1882, 15, 2572.

(24) Watanabe, Y.; Tsuji, Y.; Ohsugi, Y. Tetrahedron Lett. 1981, 22, 2667-2670.

(25) Larock, R. C.; Kuo, M. Y. Tetrahedron Lett. 1991, 32, 569-572.

(26) Cho, C. S.; Kim, J. S.; Oh, B. H.; Kim, T. J.; Shim, S. C.; Yoon, N. S. Tetrahedron 2000, $56,7747-7750$.

(27) Cho, C. S.; Oh, B. H.; Kim, J. S.; Kim, T. J.; Shim, S. C. Chem. Commun. 2000, 18851886.

(28) Arisawa, M.; Theeraladanon, C.; Nishida, A.; Nakagawa, M. Tetrahedron Lett. 2001, 42, 8029-8033.

(29) Theeraladanon, C.; Arisawa, M.; Nishida, A.; Nakagawa, M. Tetrahedron 2004, 60, 3017-3035. 
(30) Arisawa, M.; Terada, Y.; Theeraladanon, C.; Takahashi, K.; Nakagawa, M.; Nishida, A. J. Organomet. Chem. 2005, 690, 5398-5406.

(31) Hegedus, L. S.; Allen, G. F.; Bozell, J. J.; Waterman, E. L. J. Am. Chem. Soc. 1978, 100, 5800-5807.

(32) Mahanty, J. S.; De, M.; Das, P.; Kundu, N. G. Tetrahedron 1997, 53, 13397-13418.

(33) Cho, C. S. J. Organomet. Chem. 2005, 690, 4094-4097.

(34) Korivi, R. P.; Cheng, C. H. J. Org. Chem. 2006, 71, 7079-7082.

(35) Cho, C. S.; Kim, B. T.; Kim, T. J.; Shim, S. C. Chem. Commun. 2001, 2576-2577.

(36) Van Der Mierde, H.; Van Der Voort, P.; De Vos, D.; Verpoort, F. European Journal of Organic Chemistry 2008, 1625-1631.

(37) Diamond, S. E.; Szalkiewicz, A.; Mares, F. J. Am. Chem. Soc. 1979, 101, 490-491.

(38) Diamond, S. E.; Mares, F.; Szalkiewicz, A. Fundam. Res. Homogeneous Catal. 1979, 3, 345-358.

(39) Baudequin, C.; Brunet, J.-J.; Rodriguez-Zubiri, M. Organometallics 2007, 26, 52645266.

(40) Brunet, J. J.; Cadena, M.; Chu, N. C.; Diallo, O.; Jacob, K.; Mothes, E. Organometallics 2004, 23, 1264-1268.

(41) Rodriguez-Zubiri, M.; Anguille, S.; Brunet, J.-J. J. Mol. Catal. A 2007, 271, 145-150.

(42) Dub, P. A.; Rodriguez-Zubiri, M.; Baudequin, C.; Poli, R. Green Chem. 2010, 13921396.

(43) Dub, P. A.; Daran, J.-C.; Levina, V. A.; Belkova, N. V.; Shubina, E. S.; Poli, R. J. Organomet. Chem. 2011, 696, 1174-1183.

(44) Dub, P. A.; Béthegnies, A.; Poli, R. Eur. J. Inorg. Chem. 2011, 5167-5172.

(45) Dub, P. A.; Béthegnies, A.; Poli, R. Organometallics 2012, 31, 294-305.

(46) Béthegnies, A.; Daran, J.-C.; Poli, R. Organometallics 2013, 32, 673-681.

(47) Michon, C.; Medina, F.; Capet, F.; Roussel, P.; Agbossou-Niedercorn, F. Adv. Synth. Catal. 2010, 352, 3293-3305.

(48) Brunet, J. J.; Chu, N. C.; Diallo, O. Organometallics 2005, 24, 3104-3110.

(49) Anguille, S.; Brunet, J.-J.; Chu, N. C.; Diallo, O.; Pages, C.; Vincendeau, S. Organometallics 2006, 25, 2943-2948.

(50) Beller, M.; Thiel, O. R.; Trauthwein, H.; Hartung, C. G. Chem. Eur. J. 2000, 6, 25132522.

(51) Wang, X.; Widenhoefer, R. A. Organometallics 2004, 23, 1649-1651.

(52) Rodriguez-Zubiri, M.; Anguille, S.; Brunet, J.-J. Journal of Molecular Catalysis aChemical 2007, 271, 145-150.

(53) Wu, Q. Q.; Duan, X. Y.; Song, Q. H. Journal of Physical Chemistry C 2011, 115, 2397023977.

(54) Ashleysm.J; Johnson, B. F. G.; Lewis, J.; Douek, I. J. Chem. Soc., Dalton Trans. 1972, 1776-1780.

(55) Pryadun, R.; Sukumaran, D.; Bogadi, R.; Atwood, J. D. J. Am. Chem. Soc. 2004, 126, 12414-12420.

(56) Bennett, M. A.; Nyholm, R. S.; Lewis, J.; Kouwenhoven, H. W. Journal of the Chemical Society 1964, 4570-\&.

(57) Garrou, P. E.; Hartwell, G. E. J. Organomet. Chem. 1974, 71, 443-452.

(58) Herberhold, M.; Schmalz, T.; Milius, W.; Wrackmeyer, B. Z. Anorg. Allg. Chem. 2002, 628, 437-445. 
(59) Kozuch, S.; Shaik, S. Acc. Chem. Res. 2011, 44, 101-110.

(60) Bailar, J. C., Jr.; Itatani, H. J. Am. Chem. Soc. 1967, 89, 1592-1599.

(61) Reilly, J. R.; Hickinbottom, W. J. Journal of the Chemical Society, Transactions 1920, $117,103-137$.

(62) Emerson, W. S.; Robb, W. D. J. Am. Chem. Soc. 1939, 61, 3145-3146.

(63) Lantz, R. L.; Obellianne, P. Bull. Soc. Chim. Fr. 1956, 311-317.

(64) Roberts, R. M.; Vogt, P. J. Org. Synth. 1958, 38, 29-31.

(65) Merger, F.; Schroff, L. Ger. Pat. 2,618,033 1977.

(66) Cocker, W.; Turner, D. G. J. Chem. Soc. 1941, 143-145.

(67) Utermohlen, W. P., Jr. J. Org. Chem. 1943, 8, 544-549.

(68) Angelo, M. M.; Capps, D. B.; Culbertson, T. P. US 4,207,320 1980.

(69) Takahashi, T.; Satake, K. Yakugaku Zasshi 1952, 72, 463-468.

(70) Jimenez, O.; Muller, T. E.; Schwieger, W.; Lercher, J. A. J. Catal. 2006, 239, 42-50.

(71) Dub, P. A.; Poli, R. J. Am. Chem. Soc. 2010, 132, 13799-13812.

(72) Brunet, J.-J.; Chu, N.-C.; Rodriguez-Zubiri, M. Eur. J. Inorg. Chem. 2007, 4711-4722.

(73) Beller, M.; Trauthwein, H.; Eichberger, M.; Breindl, C.; Herwig, J.; Muller, T. E.; Thiel, O. R. Chem. Eur. J. 1999, 5, 1306-1319.

(74) Beller, M.; Trauthwein, H.; Eichberger, M.; Breindl, C.; Muller, T. E. Eur. J. Inorg. Chem. 1999, 1121-1132.

(75) Dub, P. A.; Rodriguez-Zubiri, M.; Daran, J.-C.; Brunet, J.-J.; Poli, R. Organometallics 2009, 28, 4764-4777. 